\title{
IDENTIDADE ÉTNICA, MOVIMENTO SOCIAL E LUTAS PELO TERRITÓRIO EM COMUNIDADES QUILOMBOLAS: O CASO DE ACAUÃ (RN)
}

\author{
Alberto Gutiérrez Arguedas* \\ Universidade da Costa Rica **
}

Resumo: Desde finais da década de 1980 emergem na cena política brasileira as comunidades quilombolas, constituindo-se como novos sujeitos coletivos e grupos étnicos, como parte de um processo mais amplo de mobilização de grupos auto-denominados 'comunidades tradicionais'. Uma das características distintivas da emergência etno-política quilombola é o caráter territorial das lutas, daí que o presente trabalho se proponha a compreender os processos de territorialização protagonizados pelas comunidades quilombolas no Brasil, relacionando três categorias profundamente imbricadas: identidade étnica, movimento social e lutas por afırmação territorial. As reflexões teórico-conceituais são complementadas com um estudo de caso, onde se expõe o processo vivenciado nos últimos quinze anos pela comunidade quilombola de Acauã, no Rio Grande do Norte (RN).

Palavras-chave: Comunidade quilombola; Acauã-RN; Território-territorialidade; Emergência étnica.

\section{ETHNIC IDENTITY, SOCIAL MOVEMENT AND STRUGGLES FOR TERRITORY IN QUILOMBOLAS COMMUNITIES: THE CASE OF ACAUÃ (RN).}

Abstract: In the late 1980s, the quilombola (or maroon) communities emerged on the Brazilian public scene, establishing themselves as new collective subjects and ethnic groups, inscribed in a broader process of mobilization of the self-denominated 'traditional communities'. One of the distinguishing characteristics of this quilombola ethno-political emergence is the territorial nature of the struggles, that's why this work aims to understand the territorialization processes lead by these communities, relating three imbricated categories: ethnic identity, social movement and struggle for territorial affirmation. The theoretic and conceptual reflections are complemented with a case study, exposing the process experienced in the last fifteen years by the maroon community of Acauã in Rio Grande do Norte (RN) .

Keywords: Quilombola community; Acauã-RN; Territoryterritoriality; Ethnic emergence. 


\section{Introdução}

A visibilidade e protagonismo que as comunidades quilombolas têm na atualidade dentro do espaço público na sociedade brasileira são uma conquista relativamente recente. Inclusive, a própria (auto)denominação de "comunidades quilombolas" se trata de uma construção identitária emergente, associada a um processo de luta por direitos e reconhecimento por parte destes grupos frente à sociedade e ao Estado brasileiro, movimento que tomou força e consistência desde finais da década de 1980 e inícios da década de 1990. Quilombola nos remete a uma configuração étnica e territorial com forte conteúdo político ou, em palavras de Leite (2000) uma forma de organização, a dimensão política de uma formação social diversa.

Nesse processo de emergência étnica e política, território é uma palavra chave pois a luta pelo reconhecimento dos territórios ocupados pelas comunidades quilombolas se constitui como o eixo estruturante das pautas reivindicatórias destes grupos, os quais articularam um movimento social de abrangência nacional nas últimas duas décadas. Além dos quilombolas, nesse período emergiram outros grupos e coletividades englobados dentro de uma denominação genérica de 'comunidades tradicionais', com uma dimensão territorial determinante. De acordo com Cruz (2014), há uma forte valorização material e simbólica do espaço, uma territorialização das lutas sociais.

Através do presente artigo buscamos contribuir para uma melhor compreensão dos processos de territorialização e emergência étnica protagonizados pelas comunidades quilombolas no Brasil contemporâneo, à luz do que vem acontecendo na comunidade de Acauã, no Rio Grande do Norte (RN), nos últimos quinze anos.

A primeira parte do texto reflete sobre a emergência das comunidades quilombolas na cena política brasileira e a construção de direitos territoriais por parte deles, processo no qual se constituíram como novos sujeitos coletivos e grupos étnicos, trazendo à tona especificidades e demandas que durante muito tempo permaneceram invisibilizadas. Na sequência, analisamos o processo de luta por afirmação territorial levado à frente pela comunidade quilombola de Acauã nos últimos quinze anos, período no qual se autoidentificaram como um grupo etnicamente diferenciado e formalizaram a organização política da comunidade, reivindicando direitos perante o Estado, sobretudo o direito à posse definitiva sobre o território historicamente ocupado.

Em termos metodológicos, a estratégia utilizada se baseou na combinação de diferentes tipos de fontes e técnicas de pesquisa. De um lado, realizou-se uma ampla pesquisa bibliográfica em livros, artigos e teses, em relação com o surgimento dos chamados 'novos' movimentos sociais no Brasil e na América Latina, dos quais as comunidades quilombolas no Brasil e suas lutas pelo direito ao território vêm sendo um exemplo vivo. Por outro lado, consultaram-se relatórios, textos e outros materiais divulgados por instituições governamentais, movimentos sociais e ONGs, sendo necessária a revisão do marco jurídico-normativo relativo à politica de regularização dos territórios quilombolas.

Finalmente, houve um componente importante de trabalho de campo na comunidade de Acauã, RN, entre junho 2013 e setembro 2014, onde se teve a oportunidade de vivenciar de perto uma dentro dos milhares de lutas quilombolas por direitos e território, conversando com os protagonistas e participando de diversos momentos do dia a dia da comunidade (reuniões da Associação de Moradores, trabalho na roça, trilhas, oficinas com as crianças, dentre outras atividades). Além da observação participante desse cotidiano em Acauã, foram realizadas um total de 09 entrevistas semiestruturadas, tanto com alguns moradores quanto com expertos e informanteschaves na matéria, algumas das quais aparecem citadas neste artigo.

\section{Lutas sociais, lutas territoriais}

A emergência das comunidades quilombolas como novos atores sociais e políticos ocorre num período de fortes transformações nas relações de poder, não só no Brasil, mas em escalas continental e até mesmo mundial. O fim de uma ordem geopolítica (conhecida como guerra fria desde o olhar dos centros de poder global) marca o surgimento de novos tipos de conflitos e lutas sociais. Percebe-se o advento de formas alternativas de ação política, tanto no meio urbano quanto no rural, assim como um intenso debate teórico-político que busca compreender tais movimentos e transformações. Da mesma forma que mudaram os modos de dominação, também mudaram as manifestações da dissidência e da resistência. Estas transformações distinguem os "novos" movimentos sociais do "velho" movimento sindical e de partido (Zibechi, 2007).

A afirmação de identidades e diferenças étnicas é uma das características mais marcantes destes 'novos' movimentos. Por isso, mais do que um surgimento, seria mais apropriado falar de visibilização de novos tipos de conflitividade social. Segundo Bartolomé (2002) a dimensão étnica de muitos conflitos sociais na América Latina esteve "invisível" - mas não por isso inexistente - durante muito tempo, descaracterizados sob 
denominações como 'revoltas camponesas', 'demandas agrárias' ou enfrentamentos com grupos tribais "não civilizados".

A princípio, esses "novos" protagonistas não estavam previstos para entrar em cena. Os processos de desnacionalização (neoliberalismo) e reorganização societária na América Latina ensejaram a emergência na cena política exatamente daqueles que, desde sempre, ficaram à margem da formação dos Estados (PortoGonçalves, 2006c). As lutas indígenas, quilombolas e dos povos tradicionais em diversos países do continente obrigaram a levar em consideração outras dimensões constitutivas da exclusão e da dominação social, para além das desigualdades de classe que, sabemos, são determinantes, mas não são as únicas. De acordo com Cruz (2014, p. 39) estes movimentos criaram um "complexo emaranhado de ideias e práticas emancipatórias que desafiam as antigas formas de entender a emancipação social", expressas através da afırmação de múltiplas identidades.

Vemos em diversos lugares do continente a afirmação daqueles que historicamente foram negados e invisibilizados no espaço público e que, para muitos, eram simplesmente um resquício do passado. Os camponeses, indígenas e afrodescendentes, longe de serem personagens anacrônicos, tornam-se protagonistas da invenção e da construção de outros futuros possíveis. Ressignificam suas memórias, tradições comunitárias e ancestralidade na construção de projetos alternativos de produção e organização comunitárias (Cruz, 2014), num processo que podemos interpretar como uma politização do tradicional.

O tradicional, hoje, é acionado como uma forma de fortalecer os laços comunitários e manter um modo de vida num determinado território. A afirmação de territorialidades e identidades territoriais 'tradicionais' se coloca como contraposição consciente a um projeto cultural e discursivo colonizador (Cruz, 2007). De acordo com Almeida (2008), a comunidade tradicional, assim como a concebemos hoje, se constitui na passagem de unidade afetiva a unidade política de mobilização.

O novo mapa de conflitividade social nos mostra um agressivo processo de expansão da fronteira agrícola, mineira, energética e sobre territórios com importantes reservas de recursos naturais (modernização conservadora), impulsada por um novo marco regulatório imposto na década de 1990 (Svampa, 2008). As leis e marcos normativos são cada vez mais permissivas com a instalação de grandes empresas transnacionais (que desfrutam de uma série de privilégios como exonerações fiscais), com graves impactos ambientais, sanitários e produtivos, e grandes prejuízos para a vida das comunidades.
As novas formas de participação cidadã e comunitária que vem sendo construídas nesse período, sobretudo nos países e regiões periféricas, têm como característica distintiva a defesa dos territórios e dos recursos naturais frente a tais ameaças e intervenções. As comunidades tradicionais, muitas delas localizadas nas "fronteiras" da territorialidade capitalista, sofrem estes impactos de forma mais severa, como pode ser constatado no caso brasileiro e latino-americano, onde os conflitos territoriais cada vez mais envolvem a esses grupos (Porto-Gonçalves, 2006a).

O conceito de território oferece muitas possibilidades teóricas e políticas para compreender esses complexos processos de reorganização social que estão em curso no mundo todo. De acordo com Porto-Gonçalves (2011), tal conceito convencionalmente está associado ao Estadonação, isto é, a uma determinada configuração espacial do poder (territorialidade) que se assume como natural e única, mas que no fundo representa a afirmação de alguns grupos/setores sobre a negação/invisibilização de outros. Por esse motivo, normalmente se pensa em território como um "objeto", fixo e estável, dado e definitivo, pois as relações de poder que o configuraram são naturalizadas.

Contrário a esta visão "clássica", os territórios são sempre criações de sujeitos sociais e históricos que através deles buscam se afirmar e instituir, portanto, são dinâmicos e mutáveis, e neles se materializam as contradições e conflitos da sociedade. Não podemos compreender 0 território se não consideramos as diferentes territorialidades e os processos de territorialização que os constituíram (Porto-Gonçalves, 2006b).

Nesse sentido, as lutas e conflitos sociais se apresentam como espaços extremamente ricos e férteis de criação, tanto política quanto epistémica. Ao lutar para transformar uma ordem social determinada, os atores em movimento (movimentos sociais) estão lutando por instituir outras configurações territoriais possíveis. Os conflitos territoriais se dão naqueles "pontos" do espaço geográfico onde uma ordem social dominante não é aceita passivamente, é questionada e confrontada, portanto, são os espaços de conflito onde "outros mundos possíveis" lutam por se afirmar. Estamos num mundo "em busca de novas territorialidades", usando a expressão de Porto-Gonçalves (2002), sendo as lutas das comunidades quilombolas um exemplo dessas novas territorialidades que se configuram em meio dos conflitos e lutas sociais.

De acordo com Cruz (2014), estamos frente a uma territorialização das lutas sociais, tanto no Brasil quanto na América Latina como um todo. As 'novas' lutas sociais são, sobretudo, lutas territoriais. Há uma forte valorização material e simbólica do espaço, na 
qual o território e as territorialidades são fundamento das estratégias de afirmação de direitos e autonomia por parte dos movimentos sociais (Cruz, 2014). Nesse sentido, as lutas que são travadas em diversos lugares do Brasil e da América Latina são mais do que lutas pelo reconhecimento e titularidade formal sobre um determinado espaço, mas têm a ver também com reconhecimento de um determinado modo de viver nesse espaço, pelo respeito que merecem suas histórias, seus costumes e suas criações (Gutiérrez, 2015). Tais movimentos ultrapassam o sentido estrito das organizações camponesas clássicas, estruturadas ao redor da classe social, e incorporam uma politização da cultura e dos diversos modos de vida construídos por cada grupo ao longo de sua trajetória específica (campesinatos, em plural), dando muita importância ao reconhecimento das diferenças.

Por esse motivo, na perspectiva de Porto-Gonçalves (2006a), mais que lutas pela terra são lutas pelo território. Não é só a luta pela terra num sentido estritamente produtivo, como uma base para assegurar as condições de reprodução material, mas pelo território, que além de ser o abrigo, fonte de recursos que permitem a vida, é definido culturalmente como um princípio de identificação e pertencimento, carregado de valores e memórias. 0 deslocamento conceitual e discursivo assinala uma abordagem mais complexa da questão fundiária que, assim, vai além da redistribuição de terras e torna-se um problema centrado nos processos de ocupação e afirmação territorial (Cruz, 2014).

Para Porto-Gonçalves (2006a) pensar a terra a partir do território significa pensar politicamente a cultura, e territorializar significa ter poder e autonomia para estabelecer determinado modo de vida num espaço. Em entrevista com a Comissão Pastoral da Terra (CPT) em $2009^{1}$ o geógrafo não poderia ser mais claro: "Quando falamos que queremos ser reconhecidos pela nossa territorialidade, não queremos só a terra, queremos um sentido determinado de estar na terra, queremos o respeito ao nosso modo específico de estar na terra".

No Brasil, a emergência de novos movimentos sociais está intimamente ligada aos processos de reconhecimento de suas territorialidades específicas, como vem sendo destacado por Almeida (2008). Primeiro foram os indígenas, agrupados em torno da UNI (União das Nações Indígenas), o Movimento dos Sem Terra e o Conselho Nacional dos Seringueiros, na década de 1980. Mais tarde, no início da década de 1990, surgem como novos protagonistas as quebradeiras de coco babaçu, os quilombolas e outros agrupamentos auto-denominados tradicionais como os castanheiros e os ribeirinhos e, mais recentemente, as comunidades de fundo de pasto (sertão nordestino) e dos faxinais (Paraná).

'Entrevista disponível no site: http://cptalagoas.blogspot.com.br/2009/09/ entrevista-prof-carlos-walter-porto.html.
Esses grupos se colocaram na cena política constituída, consolidaram seus movimentos e articularam estratégias de defesa de seus territórios. E além de defendê-los, reivindicam o reconhecimento jurídicoformal de suas formas tradicionais de ocupação e uso dos recursos naturais, geralmente caracterizadas como de uso comum (Almeida, 2008). 0 reconhecimento legal das territorialidades específicas desses grupos encontra grandes dificuldades, sobretudo porque rompe com a invisibilidade social que historicamente caracterizou essas formas de apropriação dos recursos, baseadas no uso comum e em fatores culturais intrínsecos. As distintas modalidades de apropriação comunitária muitas vezes não encontram correspondência formal no ordenamento jurídico e na ação do Estado, estruturado ao redor do conceito de propriedade privada. Esse autor destaca a relação íntima entre a perspectiva identitária e a noção de territorialidade:

[...] Foi exatamente este fator identitário e todos
os outros fatores a ele subjacentes, que levam as
pessoas a se agruparem sob uma mesma expressão
coletiva, a declararem seu pertencimento a um povo
ou grupo, a afirmarem uma territorialidade específica
e a encaminharem organizadamente demandas face
ao Estado, exigindo o reconhecimento de suas formas
intrínsecas de acesso à terra [...] (Almeida, 2008, p. 30).

Esses 'novos' protagonistas que entram na cena política conseguem se posicionar e se fazer visíveis, articulando diversas estratégias discursivas e de ação, que atribuem um conteúdo emancipatório para as culturas tradicionais, normalmente vistas como sinônimo de conservadorismo ou "entrave ao desenvolvimento" (Cruz, 2014). Nesse antagonismo e choque de visões de mundo e projetos políticos, a conflitividade se revela rica de possibilidades teóricas e políticas, pois é nela que as bifurcações possíveis se tornam reais ou não (Porto-Gonçalves, 2006c). Daí que os processos de territorialização protagonizados por comunidades tradicionais tenham um valor estratégico pois, apesar de que seu domínio territorial não seja necessariamente extenso, aportam elementos que obrigam a avaliar a pertinência de outros tipos de territorialidade no mundo contemporâneo, outros valores e horizontes de significado.

\section{Quilombolas: afirmação territorial e emergência étnica}

Os quilombos, desde suas origens, foram exemplo de organização social, muitas vezes em situações no limite da sobrevivência. Isto é, não são algo novo na história do Brasil, nem do continente americano (conhecido com 
outros nomes em outros países) $)^{2}$. Constitui uma questão relevante desde os primeiros focos de resistência ao escravismo colonial, reaparece com a Frente Negra Brasileira, nas décadas de 1930 e 1940, e retorna à cena política nas lutas pela democratização do país, sobretudo a partir das décadas de 1970 e 1980 (Leite, 2000).

Em cada momento histórico buscaram estratégias possíveis para se afirmar frente aos seus antagonistas. No entanto, o momento político atual apresenta algumas especificidades, que marcam o recorte que nos propomos estudar neste trabalho. 0 movimento quilombola, hoje, dialoga com antagonismos distintos, o que pressupõe novas estratégias de luta, linguagens, representações e práticas (Souza, 2008).

Um dos marcos desse novo momento é a Constituição de 1988, onde podemos perceber que o quilombo como categoria jurídica experimenta uma inversão de valores. Ou seja, depois de ter sido criminalizado e penalizado durante os períodos colonial e imperial e de ter desaparecido da base legal brasileira durante cem anos (entre 1888 e 1988), o quilombo reaparece nesta Constituição, agora como uma categoria de acesso a direitos, e operando com o princípio da auto-definição. Reverte-se uma história de não reconhecimento da cidadania da população negra e, assim, a carta magna se mostra como um divisor de águas, que inaugura um novo momento em que se reconhece o caráter pluriétnico da sociedade brasileira, pelo menos formalmente.

Através de intensas mobilizações e esforços organizativos, as comunidades negras rurais, 0 movimento negro urbano e outros grupos apresentaram à Assembleia Nacional Constituinte uma proposta para incluir o direito das comunidades 'remanescentes' de antigos quilombos à posse dos territórios que ocupam. Tal proposta foi formalizada por parlamentares envolvidos em tais movimentos e na luta antirracista ${ }^{3}$. Como resultado disso foi instituído esse direito no Artigo 68 do Ato das Disposições Constitucionais Transitórias $(\mathrm{ADCT})^{4}$.

Segundo Souza (2008) o debate sobre a titulação de terras quilombolas não ocupou no fórum constitucional um espaço de grande destaque e não representou um assunto muito polêmico. Suspeita-se que tenha sido aceitado pelas elites ali presentes por acreditarem que se tratava de casos raros e pontuais.

A inclusão das comunidades quilombolas como sujeitos de direito assinala a pluralização da arena pública nacional, onde atores até então invisibilizados trazem

\footnotetext{
2"[...] palenques na Colômbia e em Cuba; cumbes na Venezuela; marrons no Hait e nas demais ilhas do Caribe francês; grupos ou comunidades de cimarrones em diversas partes da América Espanhola; marrons na Jamaica, no Suriname e no sul dos Estados Unidos" (CARVALHO, 1995 apud FIABANI, 2012, p. 280).

${ }^{3}$ Destaca a participação de Carlos Alberto Caó (PDT/RJ) e Benedita da Silva (PT/RJ). ${ }^{4}$ Artigo 68 do ADCT: "Aos remanescentes das comunidades dos quilombos que estejam ocupando suas terras é reconhecida a propriedade definitiva, devendo o Estado emitir-lhes os respectivos títulos".
}

à tona suas especificidades (Cardoso e Gomes, 2011). Apesar da grande diversidade de origens e contextos em que estas comunidades estão inseridas, há elementos estruturais que as distinguem de outros segmentos sociais no Brasil e que os unem num projeto comum. Tanto dentro das comunidades quanto entre elas o sentimento de irmandade e a construção de uma identidade quilombola têm na dimensão político-organizativa uma força central (Souza, 2008). Como veremos no terceiro tópico do texto, esse caráter político das identidades pôde ser constatado no caso de Acauã, na qual a construção de uma identidade étnica quilombola nos últimos quinze anos tem sido uma ferramenta através do qual os moradores lutam por seus direitos, historicamente negados.

De acordo com Souza (2008) a questão quilombola começa a ganhar peso no cenário nacional em meados da década de 1990, a partir de uma série de encontros ${ }^{5}$ que reuniram aos representantes de comunidades quilombolas de vários estados, com destaque do Maranhão, do Pará e da Bahia, que já contavam com estruturas organizativas bastante atuantes. Em $1996 \mathrm{em}$ Bom Jesus da Lapa (Bahia), é conformada a Coordenação Nacional de Articulação das Comunidades Negras Rurais Quilombolas (CONAQ).

A CONAQ é a integração das organizações estaduais e locais de quilombos, constituindo-se como movimento social e diferenciando-se de outras formas organizativas como ONGs, sindicatos ou partidos políticos. De sua composição destacam-se associações, federações, coordenações e comissões, organizadas de modo "apartidário e autônomo", cuja característica principal é a luta pelos direitos das comunidades quilombolas. Segundo a própria CONAQ, atualmente a principal luta dos quilombolas se volta para a implementação de seus direitos territoriais, com uma pressão crescente para que o Estado implemente o disposto no Artigo 68 do ADCT, assim como em outros instrumentos e dispositivos formais associados a esse ${ }^{6}$.

A reivindicação do direito ao território, assim como o estabelecimento e organização do movimento quilombola, se dão em relação íntima com a construção de uma identidade étnica diferenciada. Segundo Oliveira (1999) as categorias étnicas são veículos para a organização social das diferenças, e ocorrem num contexto de interação social. É nas fronteiras da interação que cada grupo se define, enfatizando a auto-atribuição da identidade como uma característica fundamental

\footnotetext{
${ }^{5}$ De acordo com Alfredo Wagner, o termo "encontro" ganhou força a partir de 1985, quando se manifestam os primeiros indícios de uma crise na mediação exercida pelo movimento sindical. "Encontro", no léxico dos movimentos sociais, "corresponde a um mecanismo de decisão, equivalente a uma assembleia, a uma reunião deliberativa ou a uma consulta realizada pela coordenação junto àqueles que são por ela representados" (ALMEIDA, 2008, p. 23). Segundo Cruz (2014, p. 49), baseado no próprio Alfredo Wagner, trata-se de uma "forma superior de luta ou o evento maior de universalização do localizado".

${ }^{6}$ Decreto Presidencial 4.887/2003; Instrução Normativa No. 57 (2009) do INCRA; Convenção 169 da OIT (assinada pelo Brasil em 2002); Política Nacional de Desenvolvimento Sustentável dos Povos e Comunidades Tradicionais, através do Decreto 6.040/2007.
} 
(Freire, 2012). Em palavras da CONAQ (2010, p. 278):

A perspectiva da auto-definição dialoga com os critérios postos pelos próprios grupos, a partir de suas dinâmicas e de seus processos atuais. Portanto, é uma dimensão que foca no existir atual e se relaciona com a perspectiva de grupo etnicamente diferenciado, tais como são concebidas as comunidades quilombolas. 0 direito à diferença é o correspondente implícito do direito à igualdade, princípio constitucional relevante para o Estado Democrático e de Direito. Afirmar as diferenças significa perseguir a igualdade entre os grupos. Nesse princípio se fundam as ações afirmativas.

Como vem sendo destacado, a identidade étnica não é uma essência, algo dado, mas construída em função das necessidades e oportunidades do momento presente, uma construção estratégica e posicional (Cruz, 2006). Há uma inseparabilidade, uma relação íntima entre identidade e relações de poder, cultura e política. Trata-se de um conglomerado de mecanismos de diferenciação e identificação, que podem ser acionados (ou não) de acordo com os interesses dos indivíduos e grupos em questão, assim como pelo momento histórico no qual estão inseridos (Souza, 2005). Não nos deveria surpreender 0 fato de que as identidades étnicas usualmente são invocadas em situações de conflito, onde um grupo toma consciência de suas especificidades e as expressam exigindo seu reconhecimento. 0 conflito, assim, parece favorecer o surgimento de 'novos' atores sociais, assim como também de novas territorialidades.

Segundo Schmitt, Turatti e Carvalho (2002) a identidade quilombola foi constituída ao longo dos últimos 25 anos a partir da necessidade de lutar pela permanência nas suas terras de origem. Afirmam: "A identidade quilombola, até então um corpo estranho para estas comunidades negras rurais, passa a significar uma complexa arma nesta batalha desigual pela sobrevivência material e simbólica" (Schmitt, Turatti e Carvalho, 2002, p. 5). Como observou o sociólogo Boaventura S. Santos, citado por Schmitt, Turatti e Carvalho (2002), ao se relacionar identidade e questões de poder, aqueles que se veem obrigados a reivindicar uma identidade encontram-se usualmente numa posição de carência e subordinação.

Assim, ao falarmos de emergência étnica falamos do "surgimento" de novas identidades e sujeitos coletivos, antes inexistentes ou irreconhecíveis. Mas, para além disso, estamos frente a processos de emergência social e política de grupos tradicionalmente submetidos a relações de dominação. 0 antropólogo Bartolomé (2006) traz o sugestivo conceito de etnogêneses, ou seja, o surgimento recente de grupos considerados originários, velhos atores assumindo novos papéis no cenário cultural e político.

Esses novos tipos de sujeitos políticos se orientam a enfatizar sua alteridade para serem reconhecidos como tais, e assumem a identidade como um novo tipo de cidadania, isto é, como sujeitos com direitos a serem respeitados. A diferenciação é estratégica e se apresenta como uma oportunidade para transformar a situação dos atores sociais de forma dinâmica, sendo que o "ser quilombola" marca o salto de uma condição subalterna e indesejável a ser uma fonte de orgulho e identificação construtiva (Raimbert, 2012). Em Acauã, a construção de uma identidade quilombola contribuiu para reverter e combater o racismo predominante no município de Poço Branco onde, por exemplo, algumas pessoas da comunidade presentaram denúncias na delegacia da polícia local por discriminação racial, sofridas na rua e na escola, sabendo que a própria Constituição Brasileira tipifica esse tipo de ato como crime (Gutiérrez, 2015).

A emergência sociopolítica quilombola associase a processos de desestigmatizacão e novas legislações, nos quais ao assumir uma identidade podem esperar-se potenciais benefícios coletivos, aspirando aos direitos assegurados às coletividades étnicas. No entanto, assumir uma nova identidade por parte destes grupos é muito mais do que buscar potenciais benefícios assegurados em leis e dispositivos formais. A construção de uma autoimagem positiva, a recuperação da coletividade étnica de pertencimento e o fortalecimento dos vínculos comunitários são algumas das motivações dessa autodeterminação. De acordo com Bartolomé (2006, p. 57): "Recupera-se um passado próprio, ou assumido como próprio, a fim de construir um pertencimento comunitário que permita um acesso mais digno ao presente".

Nessa dialética entre o antigo e o novo, a longa duração das ocupações dos territórios quilombolas fornece peso histórico às suas reivindicações e afirmações identitárias, pois trata-se de territórios fundamentados em décadas ou inclusive séculos de ocupação efetiva (Cruz, 2014). Na maioria dos casos é um território mantido de geração em geração, sem titularidade formal nem posse individualizada, mas coletiva, daí que as lutas quilombolas busquem o reconhecimento formal de outras modalidades de apropriação do espaço, para além da propriedade privada, demandando ao Estado a instituição de novas categorias territoriais (Almeida, 2008; Cruz, 2014). A instituição dos Territórios Quilombolas na base legal brasileira assinala a construção de direitos de novo tipo, sobretudo direitos coletivos, largamente excluídos da base jurídica liberal-burguesa.

Do ponto de vista geográfico, um dos trabalhos que mais esclarece essa dimensão espacial da etnicidade e da emergência étnica é o de Ratts (2006), que utiliza o conceito de territórios etnicamente diferenciados. Manifesta-se "o novo sob a forma do diferente", isto é, como reconhecimento de uma diferença que requalifica os lugares, atribuindo-lhes novos significados e 
mobilizando novos poderes. Segundo ele, mais do que reconhecer o que já existe, devemos estar atentos às novas fronteiras étnicas que são traçadas e, junto com elas, novas territorialidades.

Devemos considerar também que essas territorialidades não se limitam necessariamente às áreas atualmente ocupadas e reivindicadas, mas que incorporam, através de relações comunitárias e de parentesco, lugares de mobilidade e extensão para além do perímetro dos grupos (Ratts, 2006). As relações de parentesco, muito resistentes no espaço e no tempo, mantêm vínculos duradouros entre as pessoas, as quais ultrapassam uma base territorial fixa. Vemo-nos obrigados a reelaborar a noção de território, pois estamos frente à configuração de territórios étnicos ao mesmo tempo "antigos e novos, permanentes e transitórios" (RATTS, 2006, p. 45). 0 mapa dos territórios etnicamente diferenciados é um mapa em movimento.

Como afirma Leite (2000, p. 333): "falar dos quilombos e dos quilombolas no cenário político atual é [...] falar de uma luta política e, também, uma reflexão científica em processo de construção". Intenso tem sido o debate desde a década de 1990 ao redor da questão quilombola, sobretudo nos movimentos sociais e no meio acadêmico. Vem-se enfatizando o fato de que o termo quilombo assumiu novos significados na literatura especializada e também para os grupos, indivíduos e organizações. Deixou de ser vista como "algo do passado" para tornarse parte integrante da sociedade contemporânea, uma realidade viva e pulsante, definida em função das dinâmicas do presente.

De acordo com Almeida (2002) qualquer invocação ao passado deve corresponder com uma forma atual de existência. Insiste na necessidade de nos libertarmos da "definição arqueológica" do quilombo, aquela definição "frigorificada", segundo a qual para existir deve ter evidências de sua existência no passado. "Se deveria trabalhar com o conceito de quilombo considerando o que ele é no presente. Não é discutir o que foi, e sim o que é e como essa autonomia foi sendo construída historicamente" (Almeida, 2002, p. 53).

Segundo o antropólogo, dentre os quilombolas são reproduzidos elencos de práticas cotidianas que asseguram vínculos solidários mais fortes e duradouros do que a alusão a uma determinada ancestralidade, construindo assim um repertório de ações coletivas e de representações frente a outros grupos. Os quilombolas expressam outras maneiras de se colocar frente aos aparatos de poder e estão vivendo um momento de profunda reorganização de sua representatividade no âmbito da sociedade civil e perante seus antagonistas históricos (Almeida, 2002). Isso é o que define os "quilombos do presente". No próximo tópico vamos ver mais de perto o que vem acontecendo numa comunidade quilombola em específico: Acauã, no município de Poço Branco, Rio Grande do Norte, que nos últimos quinze anos vem protagonizando uma luta organizada pelo reconhecimento de seu território.

\section{A luta pelo território no quilombo de Acauã, Rio Grande do Norte}

A comunidade de Acauã, também conhecida localmente como a Cunhã, está localizada no município de Poço Branco, no agreste do Rio Grande do Norte, uma região de transição entre o litoral e o semiárido, $65 \mathrm{~km}$ em direção noroeste da capital do estado, Natal, tal como mostra o Mapa 01. Esta comunidade é composta por pouco mais de 300 pessoas (entorno 60 unidades familiares), onde uma das características mais importantes e marcantes é o fato de seus membros compartilharem estreitos vínculos de parentesco e aliança.

Segundo a memória oral, a comunidade teria sido nomeada em função da pessoa que descobriu a área e fundou o local: José Acauã, também conhecido como 'Zé Cunhã', uma pessoa escravizada que fugiu do cativeiro nos canaviais de Ceará Mirim, perto do litoral potiguar, subindo pelo vale do rio que leva o mesmo nome e assentando-se nas margens desse corpo d'água, possivelmente acompanhado por outras pessoas na mesma situação. A pesar de que não existe precisão temporal desse momento de fundação, trata-se, segundo os testemunhos dos moradores atuais, de uma ocupação antiga, pois seus antepassados, inclusive os dos mais velhos, já eram nascidos e criados ali, sendo que no momento de sua chegada aparentemente não tinha ninguém na área (Valle, 2006; Valle, 2010).

De acordo com Brandão (2010, p. 352), essa longa duração de ocupação territorial é justamente o que define uma comunidade tradicional: "[...] Por oposição a todas as outras, são comunidades tradicionais aquelas que 'ali estavam' quando outros grupos humanos, populares ou não, 'ali chegaram' e ali se estabeleceram". Por esse motivo, na atual luta pelo território quilombola, os moradores de Acauã, descendentes das primeiras pessoas que povoaram o local, afirmam que "não estão tirando nada de ninguém", simplesmente recuperando o que é deles e que foi compulsoriamente arrancado (Gutiérrez, 2015). 


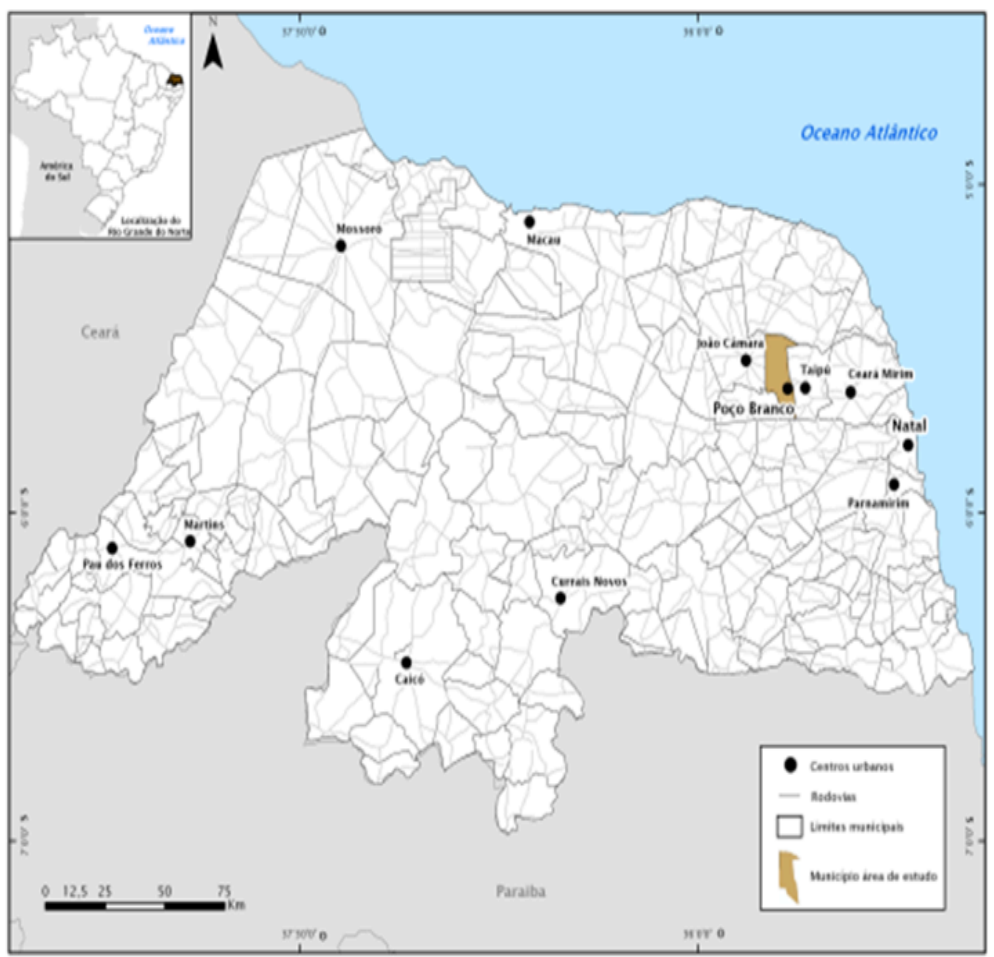

MAPA 1- Localização do Município de Poço Branco, RN.

Elaborado por Andrés Jiménez Corrales, Luiz Eduardo Virgolino Perônio e Aberto Gutiérrez Arguedas, 2014 Fonte: IDEMA.

Os fundadores se encontraram com uma terra "sem dono", que foi apossada, isto é, da qual tomaram posse para residência e produção autônoma das famílias ${ }^{7}$. A agricultura de subsistência (feijão, mandioca, milho) e, em menor medida, a pesca se constituíram como as principais atividades produtivas, nas quais a relação com o rio era fundamental, por exemplo, na renovação de nutrientes dos solos. Segundo o historiador Jair Souza, o rio Ceará-Mirim era para Acauã e as comunidades vizinhas "o rio que trazia o adubo do sertão" (Souza, 1999, p. 12). Os moradores mais velhos fazem referência a esse território 'tradicional' quilombola como uma terra livre, sem dono, solta e comum (Valle, 2006), onde podiam trabalhar e plantar à vontade, sem constrangimentos.

Nessa trajetória histórica houve um evento que marcou uma ruptura profunda na comunidade, assim como na região como um todo, que foi a construção da barragem de Poço Branco, na década de $1960^{\circ}$. Trata-se de uma grande obra de infraestrutura que atraiu muitas pessoas de vários lugares do Rio Grande do Norte para trabalhar na construção e que significou, para Poço Branco, a passagem de vila a cidade, assim como a criação do município, em 1963. Alguns dos moradores de Acauã

${ }^{7}$ Segundo as pesquisas de Valle (2006) a história das famílias de Acauã esteve ligada com modalidades variadas de ocupação econômica no campo, predominantes na parte média do rio Ceará Mirim durante boa parte do século XIX. Ali foram implantados sistemas que combinavam a pecuária com o cultivo de algodão e culturas de subsistência, como feijão, milho e mandioca, os quais permanecem ainda hoje. Ao contrário do cultivo da cana (predominante na parte baixa do rio), tais sistemas não precisam de grandes extensões de terra.

${ }^{8} \mathrm{~A}$ barragem de Poço Branco, assim como milhares de barragens no Nordeste brasileiro construídas durante o período de políticas desenvolvimentistas da ditadura militar, não era para produção de energia hidrelétrica e sim como reservatório d'água. 0 controle deste recurso, sobretudo numa região caracterizada como semiárida, sempre foi um assunto político central, onde as elites e oligarquias latifundiárias historicamente se aproveitaram de uma situação de escassez como forma de manipular, instrumentalizando a miséria alheia, num fenômeno apropriadamente nomeado de "indústria da seca" (PORTO-GONÇALVES, 2011). também trabalharam na construção, que foi terminada depois de dez anos. Diga-se de passagem, os moradores nunca foram avisados sobre o possível impacto da obra no seu território (Souza, 1999; Valle, 2006).

A barragem sobre o rio Ceará Mirim implicou a inundação de uma grande extensão de terras, atingindo diretamente o território ocupado pela comunidade de Acauã, assim como a antiga vila de Poço Branco, que foi reconstruída a $1 \mathrm{~km}$ do local original. Acauã também teve que ser reconstruída em outro local, sendo que a Cunhã Velha localizava-se na margem direita do rio e a Nova Acauã, onde estão hoje, foi construída na margem esquerda, numa pequena área de 4 hectares que conseguiram através de negociações com as autoridades municipais e os construtores da barragem. Como podemos observar, a construção da barragem de Poço Branco e todas as transformações socio-territoriais que isso provocou, estão na raiz dos conflitos territoriais que atualmente se vivem, envolvendo a comunidade de Acauã com os proprietários de terras vizinhos.

A região foi mais valorizada em termos capitalistas com a construção da barragem, atraindo novos proprietários, os quais se apropriaram de forma privada das terras até então coletivas. Os novos personagens que entram em cena, os fazendeiros, expropriaram as terras dos quilombolas e os deixaram "ilhados" numa pequena área de 4 hectares, no qual têm se mantido até hoje, inclusive proibindo durante muitos anos o acesso às águas do açude. As terras viraram pastagens para gado ou muitas delas inclusive tornaram-se improdutivas. Aparecem as cercas na paisagem de Acauã, um elemento 
até então ausente na sua configuração territorial e, assim, os moradores se veem na obrigação de trabalhar nas fazendas vizinhas, vítimas de exploração e preconceito racial. A comunidade teve que enfrentar a falta de terra e d'água durante todo esse tempo.

Esse é o contexto no qual emerge a luta atual dos moradores pela recuperação do território tradicionalmente ocupado. A luta por afirmação territorial em Acauã começou a ganhar densidade e consistência nos últimos quinze anos, período no qual se observam transformações muito significativas na vida da comunidade, bem como nas relações que estabeleceram com outros atores sociais e institucionais.

Como afirmávamos linhas atrás, as situações de conflito parecem favorecer o surgimento de novos atores sociais e novas territorialidades, tal como aconteceu em Acauã. O próprio termo "quilombola" era praticamente desconhecido a quinze anos nesta comunidade. A necessidade de lutar pela posse e pelo reconhecimento do território levou à comunidade a formalizar sua organização política (representada na figura da Associação de Moradores), ao mesmo tempo em que redefiniram e reconfiguraram sua própria identidade étnica, isto é, a forma como se representam a si mesmos e se posicionam frente a outros grupos, processo que Almeida (2002) descreve com muita clareza na sua reflexão sobre "os quilombos e as novas etnias".

A identidade como quilombolas não "caiu do céu", mas foi e é uma construção, intimamente ligada à constituição de um movimento social e político. Nesse processo de construção etnopolítica, a comunidade de Acauã se articulou com outras comunidades quilombolas do Rio Grande do Norte, unidos por reivindicações e lutas em comum, conformando um movimento quilombola em escala estadual, que se fortaleceu significativamente na última década.

Assim, a territorialidade quilombola em Acauã, além de configurar-se através das atividades cotidianas de trabalho e reprodução material da vida (agricultura, pecuária, pesca, atividades domésticas, trabalhos remunerados fora da comunidade), está atravessada por essa luta em busca do reconhecimento, com um forte conteúdo político-identitário. Na sequência vamos ver um pouco mais de perto alguns acontecimentos significativos nesse período.

A comunidade inaugurou uma nova etapa políticoorganizativa a partir da articulação com uma ONG chamada Amigos de Poço Branco, em 1997, que nesse mesmo ano seria transformada no Núcleo de Estudos Brasileiros (NEB), com a qual mantiveram parceria durante mais de uma década. Em 1998, graças à assessoria facilitada pelo NEB, conformaram a primeira associação de moradores na comunidade, a AMA (Associação de Moradores de Acauã), com o objetivo de lutar por seus direitos e representar os moradores em suas reivindicações frente ao poder público e à sociedade.

A necessidade de estarem organizados não era algo novo na história da comunidade. 0 que mudou foi a forma como essa organização se materializou. A vida política foi formalizada e institucionalizada, introduzindo no seu cotidiano novos mecanismos de ação, muitos deles estranhos e alheios às referências culturais dos moradores (predominância da linguagem escrita, instituições, documentos, ofícios, cartórios, CNPJ). De acordo com Souza (2008), na atual conjuntura as comunidades e suas organizações praticamente se veem na obrigação de formalizar-se e institucionalizar-se, pois a ação desses sujeitos políticos emergentes perpassa reivindicações formais perante o Estado, que Ihes coloca uma série de exigências para atender suas demandas.

Na política de regularização fundiária, por exemplo, um requisito solicitado às comunidades interessadas para abrir um processo é que estejam organizadas através de uma associação (legalizada e inscrita em cartório), já que no final, quando o título de terra quilombola for emitido, este será feito em nome dessa associação, que representa formalmente a comunidade.

Isso implica a conformação de um novo tipo de liderança, que atua como intermediária com os agentes, autoridades e agências governamentais, ONGs e instituições de ensino superior (Valle, 2006). Em Acauã, muitas das 'novas lideranças' são pessoas jovens, e trabalham como "representantes" do grupo frente ao poder público. Eles e elas contrastam com as lideranças mais 'tradicionais', definidas pela idade e as relações de parentesco, pessoas respeitadas pelo conhecimento que possuem sobre o passado ou por sua posição social na estruturação genealógica e histórica do grupo.

A formação de 'novas' lideranças em Acauã coincide com as observações de Bartolomé (2002), segundo o qual usualmente as lideranças das mobilizações etnopolíticas contemporâneas não acostumam ser as figuras "tradicionais" das culturas, mas membros de uma intelectualidade indígena (ou, neste caso, quilombola) que desempenham um papel de agentes interculturais (cultural brokers). Diga-se de passagem, a sobreposição destas diferentes formas de organizar as relações de poder e autoridade não está livre de contradições e dilemas, pois a própria figura de uma "liderança representativa" é uma construção típica da democracia representativa ocidental, alheia às referências culturais das comunidades tradicionais e etnicamente diferenciadas.

Foi a partir da década de 2000 que a expressão quilombola começou a fazer parte do cotidiano dos moradores de Acauã. Isso se deu como resultado de uma sinergia entre a comunidade e algumas organizações 
governamentais e ONGs, com destaque do NEB. De um lado, os moradores receberam valiosas informações sobre o que estava acontecendo em escala nacional em relação com as lutas quilombolas e a construção de direitos territoriais. Do outro lado, isso desencadeou uma reflexão na comunidade sobre a sua própria história, originada a partir da resistência ao processo de escravização sofrido.

A auto-identificação como comunidade quilombola se articulou com uma luta abrangente por direitos e cidadania, uma forma de dizer "aqui estamos, existimos e nossa história merece respeito!". No trabalho de campo podemos observar que a identidade como quilombolas, apesar de ser recente, não é uma construção puramente imaginária. É conformada a partir das experiências cotidianas e concretas vivenciadas pelas pessoas, contribuindo para dar continuidade às relações de solidariedade e ajuda mútua que historicamente sustentaram a vida em coletivo. A passagem de "negros da Cunhã" (como eram chamados pejorativamente num contexto local racista) a "comunidade quilombola de Acauã" é muito mais do que uma mudança semântica: é o reflexo de um processo de emergência étnica vivido nesta comunidade, com sua correspondente luta pelo território. As palavras de dona Bernadete Catarino da Silva, moradora de Acauã, expressam este desejo profundo por justiça e respeito, conquistados através da luta:

\begin{abstract}
Para mim hoje [ser quilombola] é uma gratificação muito grande, uma realização muito grande. Há um tempo atrás, quando falavam em quilombola, logo no início, 10 anos, 11 anos atrás, para a gente era uma vergonha na época, que a gente não tinha um conhecimento, devido ao preconceito: "os negros" como a gente era tratado, os "negros de Acauã". Então a gente foi criado assim, como esse preconceito, até humilhações, hoje é chamado de "bullying", mas antigamente a gente sofria uma humilhação terrível na escola.

Então, mais ou menos de 10 anos para cá, a gente foi se conscientizando e pra a gente foi se tornando um orgulho. A cada dia a gente foi se adaptando, buscando conhecer melhor nossa própria história, porque até então a gente não tinha tanto conhecimento assim, e hoje eu posso dizer, para mim é um orgulho. Por todas as batalhas, todas as lutas que a gente teve para mim é um orgulho ser quilombola. (Entrevista com Bernadete Catarino da Silva, 22/02/2014, em Acauã).
\end{abstract}

Depois de muito tempo de sofrer uma grande invisibilidade social ${ }^{9}$. Acauã se fez visível no mapa do Rio Grande do Norte. E não foi só Acauã: um estado como o Rio Grande do Norte que, segundo a "história oficial" ensinada nos livros didáticos escolares, não tinha negros nem tampouco indígenas, viu como em três anos (entre 2004 e 2006) um total de dez comunidades se auto-

$\overline{9}$ Segundo Leite (2013) a invisibilidade social é uma marca característica das comunidades negras rurais no Brasil. O antropólogo do INCRA-RN afirma que na pesquisa cartorial feita por essa instituição no processo de regularização do quilombo de Acauã, não há qualquer menção a uma comunidade negra ou rural no local onde os quilombolas moravam, às margens do rio Ceará Mirim. identificaram como quilombolas ${ }^{10}$ demandando seus direitos como coletividades etnicamente diferenciadas. Acauã foi a segunda no Rio Grande do Norte que formalizou essa condição perante o Estado, em 2004. A Fundação Cultural Palmares é o órgão responsável por "certificar" às comunidades quilombolas sendo esse, aliás, um requisito colocado pelo Instituto Nacional de Colonização e Reforma Agrária (INCRA) para abrir um processo de regularização fundiária.

É interessante observar que o processo de emergência étnica vivido em Acauã se configura nas novas relações e articulações sócio-políticas que a comunidade estabeleceu com outros atores sociais nesse período, sobretudo o NEB. Como bem aponta Lifschitz (2011) há uma crescente atuação de agências públicas e privadas na construção de patrimônios culturais quilombolas. o significativo papel daqueles que vieram "de fora" é abertamente reconhecido e valorizado pelos moradores do quilombo de Acauã. Nesse processo de reconstrução cultural, se acionam e ressignificam uma série de elementos e símbolos identitários chaves, anteriormente ausentes ou pouco visíveis, que remetem a um passado comum. A imagem do herói Zumbi dos Palmares pintada na sede da Associação, quebrando as correntes que simbolizam a escravidão, é um bom exemplo disso.

De acordo com a "nova" identidade atribuída pelo grupo, em 2004 a AMA se transformou em AMQA"11, Associação dos Moradores do Quilombo de Acauã, ao redor da qual vem se consolidando a formalização política da comunidade na última década, buscando legitimar sua situação como comunidade quilombola frente ao poder público e a sociedade. As demandas territoriais se constituem como as mais importantes dentro do novo projeto político dos moradores de Acauã, dentre outras como melhor acesso a serviços básicos e infraestrutura ${ }^{12}$.

0 ano de 2004 também marcou em Acauã a abertura do processo formal de regularização e titulação do território quilombola, um procedimento que desde 2003 passou a estar dentro das atribuições do INCRA, como foi instituído no Decreto Presidencial 4.887/2003. O referido Decreto incorporou o princípio da auto-determinação para definir às comunidades quilombolas; isto é, são os próprios sujeitos os que definem se são ou não parte de um grupo etnicamente diferenciado, consoante com legislação internacional assinada pelo Brasil (Convenção 169 da OIT) ${ }^{13}$.

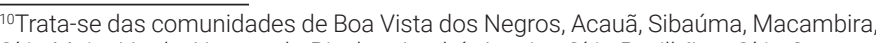
Sítio Moita Verde, Negros do Riacho, Jatobá, Aroeira, Sítio Pavilhão e Sítio Grossos (FCP, 2014). Hoje já são 22 as comunidades reconhecidas como quilombolas perante o Estado brasileiro.

${ }^{11}$ A AMQA foi formalmente instituída e regularizada em 20 de março de 2005.

${ }^{12}$ Inclusive, não devemos esquecer que esse novo projeto não se esgota nas demandas que a comunidade faz ao Estado, mas que se expressa em múltiplas ações e projetos que buscam valorizar e fortalecer a própria cultura e os vínculos comunitários. Podemos mencionar, por exemplo, uma rádio comunitária ('Rádio Melancia') que esteve no ar durante cinco anos; um grupo de teatro do oprimido chamado 'Os Filhos da Terra'; atividades de costura, e a criação de uma ateliê de roupas ('Nega Tula'); capoeira angola; mutirões; trabalho em hortas; reformas no espaço físico, dentre outros (informação cedida por Maria Lidiane Apolinário, comunicação pessoal, 06/10/2013, em Acauã).

${ }^{13} \mathrm{O}$ princípio da auto-determinação ou auto-definição coloca em obsolescência
} 


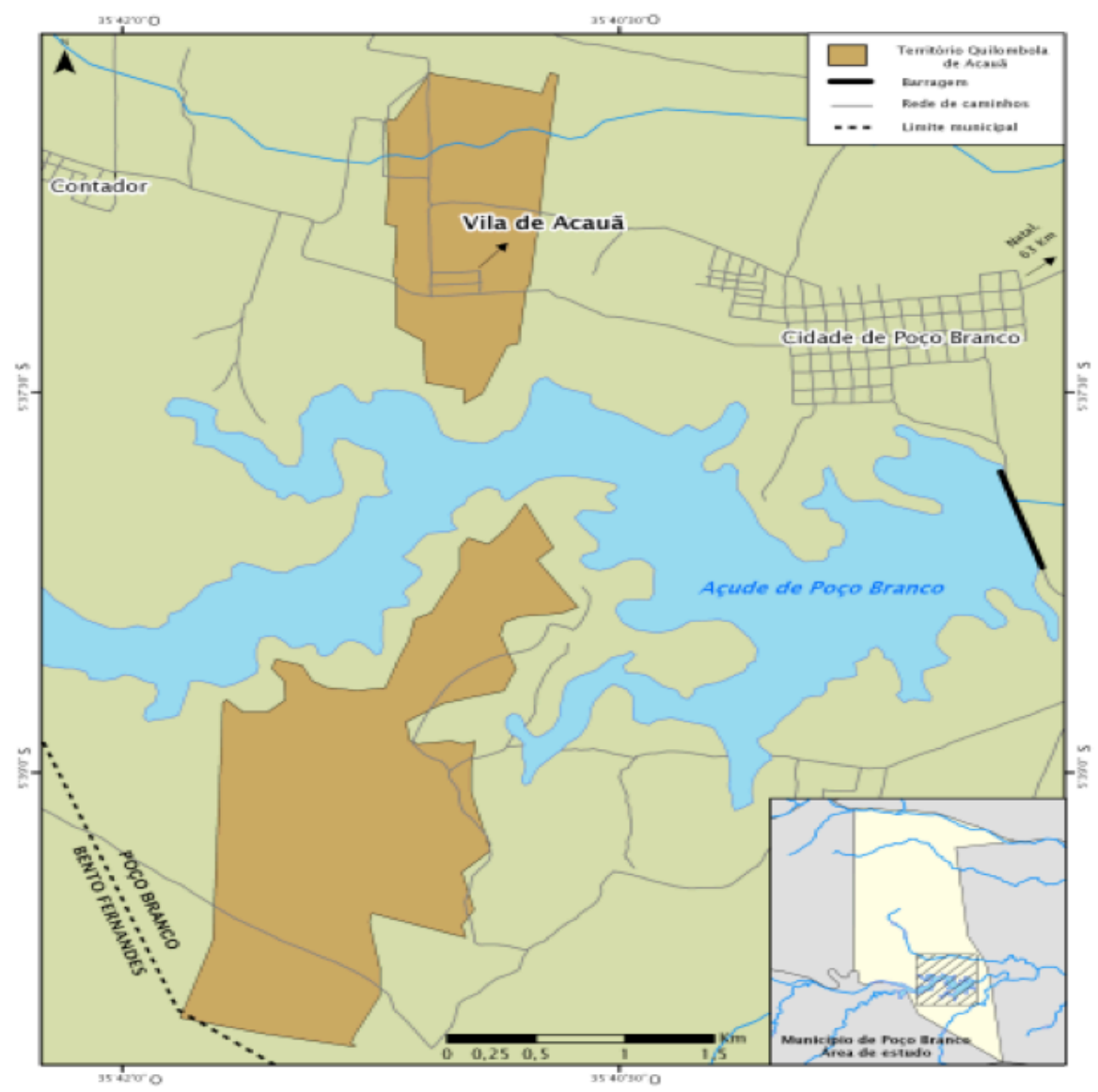

MAPA 2 - Território Quilombola de Acauã

Elaborado por Andrés Jiménez Corrales, Luiz Eduardo Virgolino Perônio e Alberto Gutiérre Arguedas, 2014 Fonte: IDEMA.

Até então a Superintendência Regional do INCRA no Rio Grande do Norte não havia realizado nenhuma ação voltada especificamente para comunidades quilombolas, tendo em vista aquela visão historicamente instituída que as via como comunidades camponesas, sem levar em conta o fator étnico (Santos e Cavignac, 2006). As comunidades, com a assistência do movimento negro local, iniciaram esta discussão e pressionaram o INCRA para atender suas reivindicações específicas em matéria territorial.

Como parte dos procedimentos formais para a regularização fundiária dos quilombos, deve ser realizado um relatório antropológico, que dilucide a trajetória histórica da(s) comunidade(s), as suas relações territoriais específicas e os atributos que lhe conferem um caráter de comunidade etnicamente diferenciada. No caso de Acauã, tal relatório foi elaborado pelo antropólogo Carlos Guilherme do Valle, professor da Universidade Federal do Rio Grande do Norte (UFRN), e publicado em agosto de 2006 (Valle, 2006).

Nele se incluiu a proposta de delimitação da área a ser regularizada como Território Quilombola de Acauã, recomendando a desintrusão dos não-quilombolas que

outros critérios anteriormente utilizados para a definição de comunidades quilombolas. Para fins da normativa anterior (Decreto 3.912/2001) uma comunidade quilombola só seria reconhecida como tal se conseguisse "atestar" através da presença de reminiscências arqueológicas ou provas documentais, sua existência anterior a 1888 (ano de Abolição do regime escravocrata), um requisito quase impossível de ser cumprido. estiverem ocupando esse espaço, "a fim de garantir plenamente a continuidade histórica e a reprodução social de Acauã como uma comunidade negra rural formada por descendentes de escravos" (Valle, 2006, p. 204). Buscase o reconhecimento formal não só das áreas atualmente ocupadas pelas comunidades quilombolas, mas também daquelas que historicamente lhes pertenceram e que em algum momento Ihes foram expropriadas. Por isso, com base nas próprias concepções de territorialidade histórica definidas em conjunto com a comunidade de Acauã, delimitou-se uma área de 540,51 hectares, a ambos os lados do açude de Poço Branco, como pode se observar no Mapa 02. Lembremos que no "outro lado", na margem sul do açude, é onde estava localizada a antiga vila de Acauã, também conhecida como a Cunhã Velha.

A delimitação do território quilombola e sua posterior demarcação representam uma significativa reconfiguração das fronteiras espaciais e identitárias em Acauã, assim como no município de Poço Branco como um todo. Dentro da área delimitada havia seis propriedades privadas e uma em situação de posse, sendo que a expropriação de cada um dos imóveis implica um procedimento administrativo e judicial por separado. Isso significa que uma extensão importante de terras que eram fazendas, propriedades privadas individuais dedicadas à pecuária extensiva, passaram a ser propriedade coletiva da comunidade quilombola. 
Importantes mudanças territoriais estão em curso em Acauã: algumas das "terras novas" já estão sendo ocupadas e trabalhadas pelas famílias, principalmente para a agricultura de subsistência (milho, feijão, mandioca, macaxeira) e a criação de animais (boi, além de porcos e galinhas, nos quintais das casas). Aliás, numa das antigas fazendas, recentemente recuperada pela comunidade, está sendo implementado um projeto de moradia popular dentro do programa do governo federal Minha Casa Minha Vida, com um total de 50 casas, que se somam às 57 que já existem na 'Vila'. Isso contribui para aliviar uma difícil situação de falta d'espaço, onde muitas pessoas se veem na necessidade de morar na mesma unidade doméstica.

Os moradores recuperaram o acesso às águas do açude, fonte de alimento (peixe), água e espaço de recreação, assim como ganharam o direito de posse sobre as terras do "outro lado" do açude, as quais inclusive são mais extensas que as da margem norte, onde estão localizados os 4 hectares da 'Vila' de Acauã. 0 senhor Sebastião Catarino da Silva, "Tota", morador de Acauã, se refere a algumas dessas reconfigurações territoriais vividas na comunidade nos últimos anos:

\begin{abstract}
Aconteceu muita mudança aqui. [Antes] não tinha onde trabalhar, praticamente era só esse quadrado aqui onde a gente mora. Teve um tempo que a gente não podia nem ir no açude, que não podia passar pela terra dos homens ali, e para lá era dos outros também. Ele tomou conta dessa terra ali todinha, do açude até o final acolá, a gente não podia passar por nenhum flanco porque era tudo fechado, tem uma estrada ali mas pra onde a gente queria passar não podia. $A$ gente ficou praticamente ilhada, só podia passar pra lá [comunidade de Contador] ou para Poço Branco, não tinha como ir pra outro canto.

Agora melhorou muito, ois desses 10,12 anos, 15 anos pra cá tem melhorado muito. A gente ganhou essas terras, a lagoa ali, tem uma terra que a lagoa quando chove junta água, pessoal planta horta, planta batata, tudo o que plantar ali colhe [...] Sei que melhorou muito, cada vez mais está melhorando mais. Tem ali o açude, quem quiser plantar nas margens ali pode plantar, não é como antigamente que ninguém podia nem chegar perto, onde quiser agora tem acesso. (Entrevista com Sebastião Catarino da Silva, 10/11/2013, em Acauã; grifos meus).
\end{abstract}

As palavras de "Tota" expressam um sentimento de otimismo bastante generalizado na comunidade, segundo o qual na última década as coisas melhoraram bastante. E não há conquista mais significativa do que ter recuperado o território dos antepassados. Porém, tais transformações não acontecem de um dia para outro, e apesar de que em termos formais as terras passaram a estar em mãos das famílias de Acauã, na realidade o que se vive é uma disputa e uma tensão, tanto territorial quanto simbólico-identitária, entre os quilombolas e os fazendeiros "brancos". A proximidade geográfica entre a 'Vila' de Acauã e a cidade de Poço
Branco, separados por apenas $2 \mathrm{~km}$ (Mapa 02), por um lado facilita o acesso a bens e serviços, mas por outro contribui para acirrar o cenário de tensão territorial. 0 mapa do território quilombola deve ser lido como um processo em movimento mais do que uma realidade estável, o que corresponde com as reflexões de PortoGonçalves (2006a), segundo o qual a construção de novas territorialidades não acontece de forma harmônica, mas sim em situações de conflito como essa.

0 procedimento legal de regularização de territórios quilombolas, como qualquer outro que busque uma ação de reforma agrária, caracteriza-se por sua morosidade e falta de celeridade, enfrentando constantemente travas e retrocessos. 0 direito territorial quilombola colocase como um "obstáculo" para os interesses das elites agrárias assim como de grandes empreendimentos agropecuários, extrativos ou de infraestrutura, públicos ou privados. A experiência mostra que dificilmente um processo desta natureza é resolvido em menos de dez anos, como informam os próprios funcionários do INCRA (Gutiérrez, 2015) ${ }^{14}$.

Segundo a historiadora Lilian Gomes (2010), essas dificuldades fazem parte da relação ambivalente que as comunidades quilombolas estabelecem com o Estadonação: de um lado, negociam com ele a garantia e efetivação dos seus direitos e, por outro lado, implica denunciar esse mesmo Estado que Ihes concedeu um lugar subalterno.

Em Acauã, foi depois de quase uma década que se materializaram os primeiros resultados, na qual os moradores conseguiram recuperar formalmente suas terras ou, pelo menos, uma parte delas. Entre 2013 e 2014 a comunidade ganhou o direito de posse sobre cinco das antigas fazendas, regularizando uma área de 310,8 hectares, nas quais as famílias já têm plenos direitos para ocupar e trabalhar nelas. Apesar de que ainda não foi emitido o título definitivo, o INCRA está facultado para dar às famílias quilombolas o direito de posse (uma espécie de título provisório) naqueles imóveis que já foram desapropriados.

Em 2007, depois de ter sido publicado o Relatório Técnico de Identificação e Delimitação (RTID), recomendando a desocupação dos não-quilombolas, veio aumentar consideravelmente a tensão social local. Naquele momento algumas famílias em Acauã ainda

\footnotetext{
${ }^{14}$ No caso de Acauã, o que realmente está entravando o processo foi uma ação judicial interposta em 2008 por um dos proprietários, na qual solicitou que a regularização do quilombo fosse declarada nula ou inválida. A ação de nulidade foi deferida na Justiça Federal do Rio Grande do Norte, o que implicou que o imóvel registrado no seu nome ficasse por fora das ações desapropriatórias. Segundo o agropecuarista Elias Azevedo da Cunha Filho, as terras em questão jamais foram ocupadas pelos moradores de Acauã. O demandante alega que não existem provas documentais da existência de um quilombo na região, e inclusive defende a inconstitucionalidade do Decreto $4.887 / 2003$, pois segundo ele viola o direito à propriedade. De acordo com o antropólogo Thiago Leite (2013) o fazendeiro conseguiu se utilizar do desconhecimento de algumas instâncias da Justiça do RN sobre a questão quilombola para anular a desapropriação de sua fazenda, onde justamente se encontram as ruinas da Cunhã Velha, na margem direita do açude. Para mais informação: http://www.cedefes.org.br/index.php?p=afro_detalhe\&id_ afro $=4458$.
} 
trabalhavam "nas terras dos outros", sob o sistema de meeiro, e depois da ordem de desapropriação, alguns dos proprietários vizinhos passaram a impedir que os moradores continuassem arrendando as áreas de terras em que vinham mantendo seus cultivos (Valle, 2010). Como podemos imaginar, a situação foi bastante dramática, chegando, inclusive, a situações de violência física explícita ${ }^{15}$.

Nos últimos anos, inclusive naquelas áreas que já foram formalmente incorporadas ao Território Quilombola, os moradores têm sofrido invasões e intimidações por parte dos ex-proprietários. Uma estratégia recorrente é de colocar gado dentro das terras em disputa, destruindo as lavouras das famílias. Essas e outras situações de conflito territorial foram registradas durante o trabalho de campo (Gutiérrez, 2015).

Por último, mas não menos importante, é o fato de que para poder compreender as dinâmicas sociais e territoriais da comunidade de Acauã, é necessário olhar para fora do perímetro ocupado e reivindicado pelo grupo, para além do local, consoante com os territórios étnicos descontínuos e em rede descritos por Ratts (2006). Muitas pessoas em Acauã, principalmente homens adultos, trabalham fora da comunidade, na cidade de Natal e sua região metropolitana, dedicados na sua maioria à construção civil. Sua rotina é um movimento cíclico entre a semana de trabalho na capital e o fim de semana na comunidade, momento em que se reencontram com seus familiares. Aqui também vemos novas territorialidades sendo construídas.

Como apontávamos linhas atrás, são as relações comunitárias, de parentesco e memória, muito resistentes no espaço e no tempo, as que em última instância definem uma identidade étnica própria e mantêm os vínculos que os definem enquanto comunidade, isto é, enquanto um grupo de pessoas com uma história e um projeto em comum, unidos por laços de afetividade e solidariedade. Cabe a nós decifrar como os territórios são construídos e reconstruídos em meio dessas dinâmicas.

\section{Considerações finais}

Ao longo deste trabalho buscamos apresentar alguns elementos que possam ajudar na compreensão dos processos de territorialização protagonizados pelas comunidades quilombolas no Brasil, através do estudo específico do que vem acontecendo em AcauãRN nos últimos quinze anos. Podemos interpretar as lutas por território tanto num sentido jurídico-formal quanto simbólico, isto é, tanto pela demarcação e titulação territoriais quanto pelo direito e o respeito à territorialidade, a um modo específico de ser e estar na terra (Porto-Gonçalves, 2006a).

A emergência das comunidades quilombolas como novos sujeitos coletivos e grupos étnicos nas últimas décadas está intimamente relacionada com os processos de luta pelo acesso à terra e ao território. Nesse período se conformou um movimento social quilombola de abrangência nacional, articulado e representado na figura da CONAQ. Tal luta implicou a criação de uma nova categoria jurídica e espacial reconhecida pelo Estado brasileiro: os Territórios Quilombolas, os quais apontam para uma pluralização da questão agrária, pois é colocado em questão o modelo de sociedade baseado na propriedade privada como única forma de acesso à terra. No universo das comunidades quilombolas no Brasil, identidade étnica, movimento social e lutas pelo território são dimensões inseparáveis, profundamente imbricadas.

O caso específico de Acauã-RN ajuda a confirmar algumas dessas observações. A adesão de uma 'nova' identidade (quilombola) foi uma forma através da qual se constituiu um movimento político na comunidade, um processo que ainda está em aberto. A construção do "ser quilombola" coincide com uma nova etapa na vida da comunidade, na qual a negritude deixa de ser motivo de vergonha e se transforma em orgulho e identificação construtiva. A história da comunidade, marcada pela resistência dos seus antepassados frente ao processo de escravização é fonte de inspiração para a construção de um presente e um futuro melhores.

Depois de quinze anos, os frutos da construção de um projeto político quilombola são hoje visíveis. A grande maioria das terras ocupadas pelos seus antepassados já foram recuperadas, tanto na prática quanto no aspecto jurídico. O território de 540,51 hectares delimitado pelo INCRA está numa fase avançada do processo de regularização. Em vez de trabalhar nas terras dos outros, hoje têm seus próprios roçados; já se acabou a época de carregar água em baldes desde lugares distantes, pois hoje cada casa conta com cisterna e encanamento; a nova geração pode desfrutar das águas do açude, sem as proibições por parte dos fazendeiros, como acontecia anos atrás. Enfim, apesar das grandes limitações e dificuldades ainda presentes em Acauã, as pessoas recuperaram sua autoestima e não hesitam em afırmar que a vida tem melhorado de forma significativa, graças à sua luta e à de seus antepassados. 
ALMEIDA, A.W.B. (2002). Os quilombos e as novas etnias. In: O’DWYER, E.C. (Org.). Quilombos: identidade étnica e territorialidade. Rio de Janeiro: Editora FGV, pp. 43-81.

(2008) Terras de quilombo, terras indígenas, "babaçuais livres", "castanhais do povo", faxinais e fundos de pastos: Terras tradicionalmente ocupadas. $2^{\mathrm{a}}$ edição. Manaus: PGSCA-UFAM.

BARTOLOMÉ, M. (2002). Movimientos indios em América Latina. Los nuevos procesos de construcción nacionalitaria. Desacatos. No. 10, pp. 148-166.

(2006) As etnogêneses: velhos atores e novos papéis no cenário cultural e político. Mana. Vol. 12, No.1, Rio de Janeiro, abril 2006, pp. 39-68.

CARDOSO, L. e GOMES, L. (2011). Movimento Social Negro e Movimento Quilombola: por uma teoria da tradução. Disponível em: <http://www.observatoriodonegro.org.br/pdf/movimento-social-negro-e-movimento-quilombola-para-teoria-da-traducao-por-lourenco-cardoso-e-lilian-gomes.pdf>. Acessado em: 10 de novembro, 2014.

CONAQ -Coordenação Nacional de Articulação das Comunidades Negras Rurais Quilombolas- (2010). Manifesto pelos Direitos Quilombolas. In: ALMEIDA, A.W.B., et al. (Orgs). Territórios Quilombolas e Conflitos. Caderno de Debates Nova Cartografia Social. Vol 1, No. 2. Manaus: UEA Edições, pp. 268-290.

CRUZ, V.C. (2006). Pela outra margem da fronteira: Território, identidade e lutas sociais na Amazônia. Dissertação de Mestrado em Geografia, Universidade Federal Fluminense. Niterói, 201 p.

(2007). Territórios, identidades e lutas sociais na Amazônia. XII Encontro da Associação Nacional de Pós-Graduação e Pesquisa em Planejamento Urbano e Regional. Belém, 21 a 24 maio 2007.

(2014). Movimentos sociais, identidades coletivas e lutas pelo direito ao território na Amazônia. In: SILVA, O.A.; SANTOS, E.M.C e COELHO NETO, A.S. (Orgs.). Identidade, Território e Resistência. Rio de Janeiro: Consequência, pp. 37-72.

-FREIRE, M.S.L. (2012) “É a luta da gente!”: Juventude e etnicidade na Comunidade Quilombola de Capoeiras (RN). Dissertação de Mestrado em Antropologia Social, Universidade Federal do Rio Grande do Norte. Natal, 171 p.

GOMES, L. (2010). 0 direito quilombola ao território: uma questão de justiça. In: ALMEIDA, A.W.B., et al. (Orgs). Territórios Quilombolas e Conflitos. Caderno de Debates Nova Cartografia Social. Vol 1, No. 2. Manaus: UEA Edições, pp. 187-196.

GUTIÉRREZ, A. (2015) Território para viver. Dinâmicas territoriais da comunidade quilombola de Acauã, Poço Branco, Rio Grande do Norte. Dissertação de Mestrado, Programa de Pós-Graduação e Pesquisa em Geografia (PPGe), Universidade Federal do Rio Grande do Norte. Natal, 200 p.

LEITE, I.B. (2000) Os quilombos no Brasil: Questões conceituais e normativas. Etnográfica. Vol. 4, No. 2, pp. 333-354.

LIFSCHITZ, J.A. (2011) Comunidades tradicionais e neocomunidades. Rio de Janeiro: Contra Capa.

OLIVEIRA, J.P. (1999) Ensaios em Antropologia Histórica. Rio de Janeiro: Editora UFRJ.

PORTO-GONÇALVES, C.W. (2002) Da geografia às geografias: um mundo em busca de novas territorialidades. In: SADER, Emir; CECEÑA, Ana Esther (Orgs), A Guerra Infinita: Hegemonia e Terror Mundial. Petrópolis: Vozes, pp.217-256.

. (2006a) A Reinvenção dos Territórios: a experiência latino-americana e caribenha. In: CECEÑA, Ana Esther et al (Orgs). Los desafíos de las emancipaciones en un contexto militarizado. Buenos Aires: CLACSO, pp. 151-197.

(2006b) De saberes e de territórios: Diversidade e emancipação a partir da experiência latino-americana. GEOgraphia, Vol. 8, No. 16, pp. 41-55.

(2006c) A geograficidade do social. Uma contribuição para o debate metodológico para os estudos de conflitos e movimentos sociais na América Latina. Revista Eletrônica da Associação dos Geógrafos Brasileiros-Seção Três Lagoas, MS. Vol. 1, No. 3, pp. 5-26.

(2011) A Globalização da Natureza e a Natureza da Globalização. $2^{a}$ edição- Rio de Janeiro: Civilização Brasileira, $461 \mathrm{p}$.

RAIMBERT, C. (2012) La ruralidad quilombola o los nuevos desafíos de la agricultura familiar en Brasil. Revista Pueblos y Fronteras Digital. Vol. 7, No. 14, pp. 48-80.

RATTS, A.P. (2006) A geografia entre as aldeias e os quilombos: Territórios etnicamente diferenciados. Em: ALMEIDA, M.G. e RATTS, A.P. (Orgs), Geografia, Leituras Culturais. Niterói: Editora Alternativa, pp. 29-48. 
SANTOS, F. L.A; CAVIGNAC, J. (2006) O processo de regularização fundiária dos territórios quilombolas no Rio Grande do Norte: uma experiência compartilhada. In: Núcleo de Estudos Agrários e Desenvolvimento Rural. $O$ Incra e os Desafios para a Regularização dos Territórios Quilombolas. Brasília: MDA-INCRA, pp 159-171.

SCHMITT, A., TURATTI, M. C. e CARVALHO, M. C. (2002) A atualização do conceito de quilombo: Identidade e território nas definições teóricas. Ambiente \& Sociedade. Ano V, No. 10, pp. 1-8.

SOUZA, A.A. (2005) O levante dos "invisíveis" da história: o Movimento Indígena no Equador na década de 1990. Dissertação de Mestrado em História Social das Relações Políticas, Universidade Federal do Espírito Santo. Vitória, 191 p. SOUZA, B.O. (2008) Movimento Quilombola: reflexões sobre seus aspectos político-organizativos e identitários. Disponível em: <http://www.abant.org.br/conteudo/ANAIS/CD_Virtual_26_RBA/grupos_de_trabalho/trabalhos/GT\%2002/ barbara\%20oliveira\%20souza.pdf>. Acessado em: 20 de outubro, 2014.

SOUZA, J.F. (1999) Associação de Moradores da Acauã: a história de uma luta contra a exclusão social. Monografia de Graduação do Curso de História, Universidade Federal do Rio Grande do Norte, Natal, 50 p.

SVAMPA, M (2008) Los nuevos conflictos territoriales: el escamoteo de la cuestión. Disponível em: <http://www.cetri. be/spip.php?article562>. Acessado em: 20 de setembro, 2013.

VALLE, C.G. (2006) A comunidade quilombola de Acauã (Cunhã, Cunhã Velha): Relatório antropológico. Convênio UFRN-FUNPEC-INCRA/RN. Projeto: Identificação e delimitação dos territórios das comunidades quilombolas do estado do Rio Grande do Norte, 238 p.

(2010) Quilombolas de Acauã-Terra, história e conflito social no Rio Grande do Norte. In: ALMEIDA, A.W.B, et al. (Orgs). Territórios Quilombolas e Conflitos. Caderno de Debates Nova Cartografia Social. Vol1, No. 2. Manaus: UEA Edições, pp.131.138.

ZIBECHI, R. (2007). Autonomías y Emancipaciones. América Latina en movimiento. Lima: Universidad Nacional Mayor de San Marcos.

\section{Entrevistas}

Entrevista com Maria Lidiane Apolinário, 06 de outubro 2013, em Acauã.

Entrevista com Sebastião Catarino da Silva ("Tota"), 10 de novembro 2013, em Acauã.

Entrevista com Bernadete Catarino da Silva, 22 de fevereiro 2014, em Acauã. 